\title{
A Retrospective Study of the Prevalence of Depression among Women Attending a Mental Health Clinic in the Niger Delta Region of Nigeria
}

\author{
Izibeloko Jack-ide
}

Faculty of Nursing, Department of Mental Health, Niger Delta University, Wilberforce Island, Bayelsa, Nigeria

Corresponding author: Izibeloko Jack-ide, Faculty of Nursing, Department of Mental Health, Niger Delta University, Wilberforce Island, Bayelsa, Nigeria, E-mail: izibelokojackide@ymail.com

Received: Jan 25, 2016; Accepted: Jan 28, 2016; Published: Jan 31, 2016

Copyright: (c) 2016 Jack-ide I. This is an open-access article distributed under the terms of the Creative Commons Attribution License, which permits unrestricted use, distribution, and reproduction in any medium, provided the original author and source are credited.

\section{Abstract}

Depressive disorder is a common cause of distress and impairment in physical, social, occupational and other important aspect of life especially among women in the Niger Delta region of Nigeria has been poorly explored. This study was designed to determine the prevalence of depression among women attending the Mental Health Clinic at the Federal Medical Center, Yenagoa, Bayelsa State. A retrospective study design was used to collect data from case files from January 2009-December 2012 of women diagnosed with depression. Result shows that prevalence of depression among women ranged from $21(24.1 \%)$ in 2009, 17(19.5\%) in 2010, 16(18.4\%) in 2011 and $33(37.9 \%)$ in 2012 , with a mean prevalence of approximately (22\%) cases of depression/year. Also, more than half $(57.5 \%)$ of the women had severe form of depression, (17.2\%) had moderate form of depression while $(25.3 \%)$ had mild form of depression. Result from this study also revealed the highest prevalence of depression (39.1\%) to be within ages 20-30. At $95 \%$ confidence interval, chi-square value of 10.230 , difference (df) $8, P=0.249$, there was no statistical relationship between age and form/severity of depression among women. The need for sensitization campaign by health professionals to enlighten the public is suggested.

Keywords: Prevalence; Depression; Mental health; Mood disorder; Accessibility

\section{Introduction}

Depression is a mental health disorder characterized by a profound and persistent sadness or despair and or loss of interest in things that once were pleasurable [1]. According to Berzoff and Hayes [2], depression is a mood disorder and mood refers to the prolonged emotions that colour's psychic life. Depressive disorders often start at a young age; they reduce people's functioning and often are recurring [1]. Among the many mental health disorders that an individual can develop in his or her life cycle, depression has gain prominence especially in recent years [3]. For these reasons, depression is the leading cause of disability worldwide in terms of total years lost due to disability and it is predicted to be the leading cause of disease burden by 2030, and it is already the leading cause in women worldwide [4]. Depressive disorders are common in all region of the world, and can affect the outcome of common chronic conditions such as arthritis, asthma, cardiovascular diseases, cancer, diabetes, and obesity $[4,5]$. This increases the importance of non-communicable diseases such as depressive disorders for low income countries where only a low percentage of gross domestic products are allocated to health services [6].

Evidence show that depression has been known to impair job performance $[7,8]$ and interferes with sleep, eat, study and enjoy activities of daily living and responsible for $48 \%$ loss of productivity time $[9,10]$. Despite WHO's estimates [1] that depressive disorders will be the second leading cause of global disease burden by 2030, majority of persons affected do not have effective treatment in many developing countries. Primary care is the cornerstone of health care service but due to lack of effective and efficient management programme of depression, most of the patients are unscreened at this level $[11,12]$. Barriers to effective care and treatment in developing countries include the lack of resources, lack of trained professionals, and the social stigma associated with mental health disorders $[1,13]$.

There are few studies conducted in Nigeria to assess the prevalence of depression. Yusuf and Adeoye [14] report on prevalence of depression among civil servants in Osun State showed a high prevalent among women. Also, in another study [15] of prevalence among adults in Oyo State, reported an overall prevalence of $5.2 \%$, and that depression was prevalent among women than men (5.7\% vs $4.8 \%)$, and more in rural population. Obi and colleagues [16] reported a high prevalence of depression among health workers in Enugu, South East Nigeria. Lack of studies on depression in Nigeria makes it difficult to produce empirical and statistical evidence to emphasize the magnitude of this problem locally. Women often report at the Mental Health Clinic with an advanced form of depressive disorders and in most cases with it associated disabilities. More so, despite the seriousness of the problems of depression and its consequences among women, there are limited literatures on this subject and none in Bayelsa State, Nigeria on the prevalence of depression among 
women. Therefore, the study aims to explore the prevalence of depression among women attending the Mental Health Clinic at the Federal Medical Centre, Yenagoa from January 2009December 2012 [Table 1].

\section{Materials and Methods}

This study is a retrospective study of women diagnosed of depression and have being receiving treatment at the Mental Health Clinic, FMC, Yenagoa from January 2009-December 2012. Patient's case files were used to generate data for the study (Figures 1 and 2). The instrument is valid as they are patient's case file written and kept by trained medical personnel in the hospital and the instrument is reliable as they were records kept by qualified trained health personnel and the data obtained were certified by the Chief Psychiatrist and Nursing officer in-charge. The data collected was analysed using statistical package for scientific solution (SPSS) version 17. Approval to conduct the study was given by Ethics Committee of the hospital. To maintain confidentiality names of patients and folder numbers were substituted (Tables 2 and $3)$.

\section{Results}

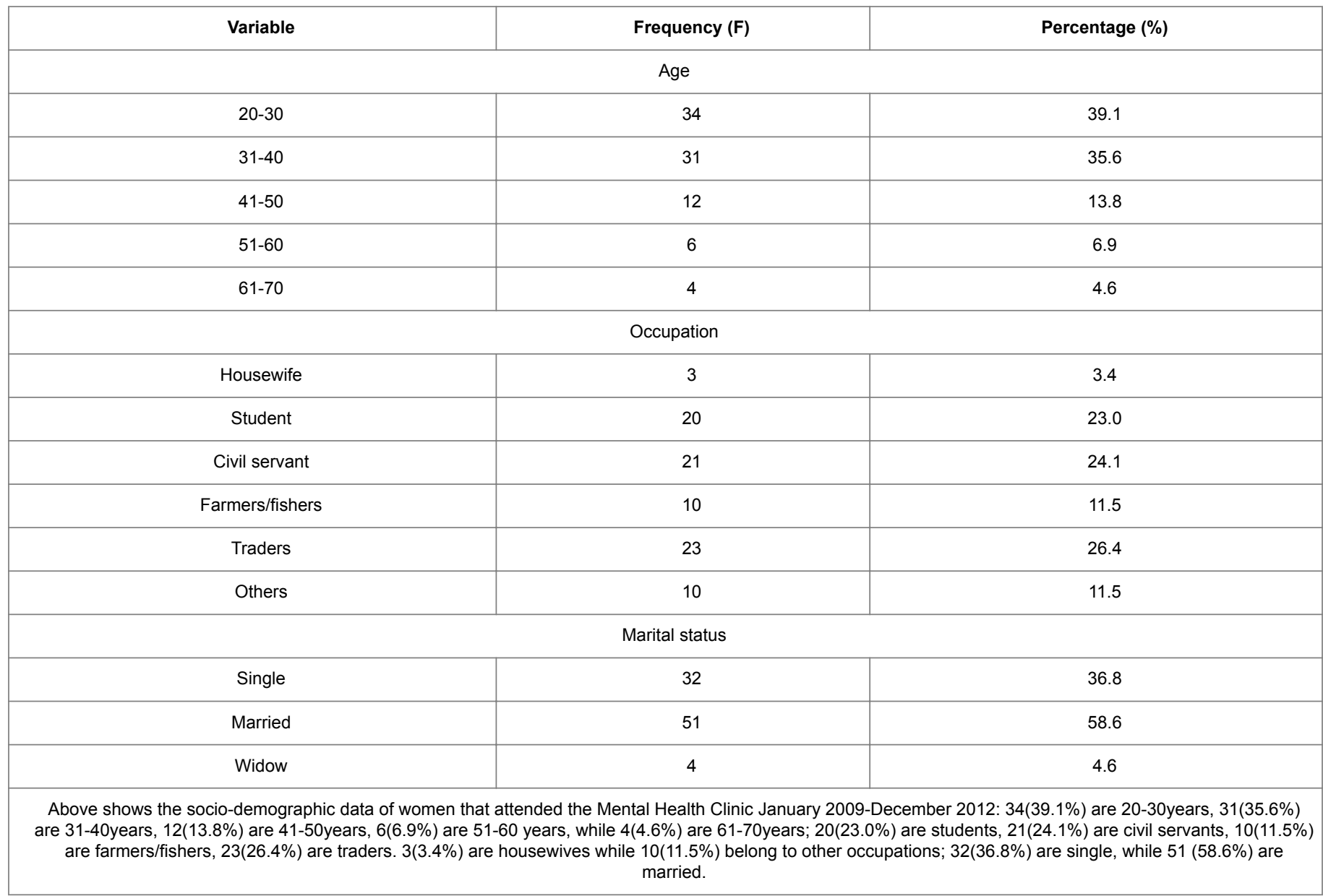

Table 2: Relationship between marital status and forms of depression among women.

\begin{tabular}{|c|c|c|c|c|c|c|}
\hline \multirow[t]{2}{*}{ Variable } & \multicolumn{3}{|c|}{ Form of Depression } & \multirow[t]{2}{*}{ Df } & \multirow[t]{2}{*}{$\mathbf{X} 2$} & \multirow[t]{2}{*}{ P-value } \\
\hline & Severe & Moderate & Mild & & & \\
\hline \multicolumn{7}{|c|}{ Marital Status } \\
\hline Single & 20 & 27 & 10 & 4 & 6.602 & 0.184 \\
\hline Married & 2 & 13 & 11 & & & \\
\hline \multirow[t]{2}{*}{ Widow } & 10 & 11 & 1 & & & \\
\hline & 50 & 15 & 22 & & & \\
\hline
\end{tabular}


Shows the relationship between marital status and forms of depression among women who attended the Mental Health Clinic of Federal Medical Centre Yenagoa, from January 2009-December 2012. At 95\% confidence interval, chi-square value of 6.602 , difference (df) 4 , $P=0.184$, there was no statistical significant relationship between marital status and form/severity of depression among women.

Table 3: Relationship between age and forms/severity of depression among women.

\begin{tabular}{|c|c|c|c|c|c|c|}
\hline \multirow[t]{2}{*}{ Variable } & \multicolumn{3}{|c|}{ Form of Depression } & \multirow[t]{2}{*}{ Df } & \multirow[t]{2}{*}{$\mathbf{X} 2$} & \multirow[t]{2}{*}{ P-value } \\
\hline & Severe & Moderate & Mild & & & \\
\hline \multicolumn{7}{|c|}{ Years } \\
\hline $20-30$ & 16 & 7 & 11 & 4 & 6.602 & 0.184 \\
\hline $31-40$ & 23 & 4 & 4 & & & \\
\hline $41-50$ & 6 & 1 & 5 & & & \\
\hline $50-60$ & 2 & 2 & 2 & & & \\
\hline \multirow[t]{2}{*}{$60-70$} & 3 & 1 & 0 & & & \\
\hline & 50 & 15 & 22 & & & \\
\hline
\end{tabular}

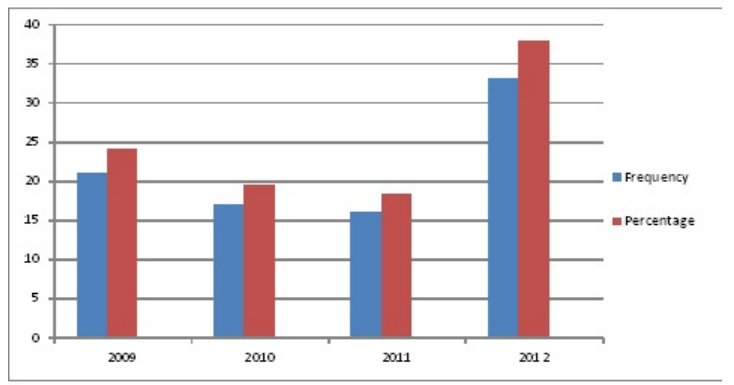

Figure 1 Above shows the prevalence of depression among women who attended and received treatment at the Mental Health Clinic of Federal Medical Centre, Ovom Yenagoa, from January 2009 - December 2012; 21(24.1\%), 17(19.5\%), 16(18.4\%) and 33(37.9\%) are the prevalence of depression for 2009, 2010, 2011 and 2012 respectively. Mean prevalence of depression for the study period is 21.75 which is approximately 22 cases of depression/year.

Figure 1: Prevalence of depression among women.

\section{Discussion}

\section{Socio-demographic data}

The result show women with depression that attended and received treatment at the Mental Health Clinic from January 2009-December 2012 was eighty seven $(n=87)$, with a mean age of 35.5 years. Most of the women (26.4\%) are traders, more than half $(58.6 \%)$ are married. Result from the finding shows women between their 3rd and 4th decade of life suffer from depression.

\section{Prevalence of depression among women}

The finding reveals the mean prevalence of depression among women attending the mental health clinic within the study period is $21 \%$ which is approximately $22 \%$. The highest prevalence was observed in 2012 (37.9\%) while the least was in 2011 (18.4\%). The prevalence observed in this study (22\%) is similar to other studies5 that reported a mean overall prevalence of $34 \%$ (range $29-66 \%$ for women). Evidence shows prevalence of depression among women to be above $30.0 \%$ [10]. This is worrisome as maternal depression may have serious consequences on children and families wellbeing.

Majority $57.5 \%$ have severe depression out of a total of 87 diagnosed cases of depression. This confirms the finding that despite the known cost effectiveness of treatment for depression, majority of people in need of care do not seeks or receives early treatment due to stigma and lack of facilities [12]. Also, it is postulated that delay in treatment of depression might reflect stigma or under-diagnosis of the disorder at an earlier stage [11]. This may explain why most of the women attending the clinic presents' with severe depression.

\section{Age distribution of depression among women}

The finding reveal prevalence of depression was highest among women ages of 20-30years. This is similar to previous report [11] that depression is more than twice as prevalence in young women than men (ages 14-25). This finding however contrasts a higher rate of depression $14.07 \%$ in women within age 60-65 in Brazil [3]. Evidence has shown depression can occur in all age groups but may be more prevalence in the reproductive age [13].

\section{Relationship between form of depression and marital status}

At $95 \%$ confidence interval, chi-square value of 10.23 , difference (df) $8, P=0.249$, there were no statistical significant relationship between marital status and form/severity of depression among women. This implies that the severity of depression is not influenced by marital status, although the finding show single women had more depression than the married women and those that are divorced. This contrast a previous study that reported a higher incidence of depression 
among married women than the unmarried and divorced in health workers of Enugu State [16]. The finding is similar with an earlier study in Nigeria that reported significant difference in the prevalence of depression among civil servants on the basis of marital status and reported that being married insulate people from depression [14]. Also, a study conducted in an urban South India city that showed prevalence of depression was higher among divorced (26.5\%) and widowed (20\%) compared to married subjects $(15.4 \%)$ in their study population [17].

\section{Relationship between form of depression and age}

At $95 \%$ confidence interval, chi-square value of 10.230 , difference (df) $8, P=0.249$, there was no statistical significant relationship between age and form/severity of depression among women. This implies that age do not determine the severity of depression although severity was highest at the end of third to fourth decade of life. Similarly, it was reported [3] that the maximum depression risk occurs at the age of 43.8 for women but did not predict severity of depression at this age.

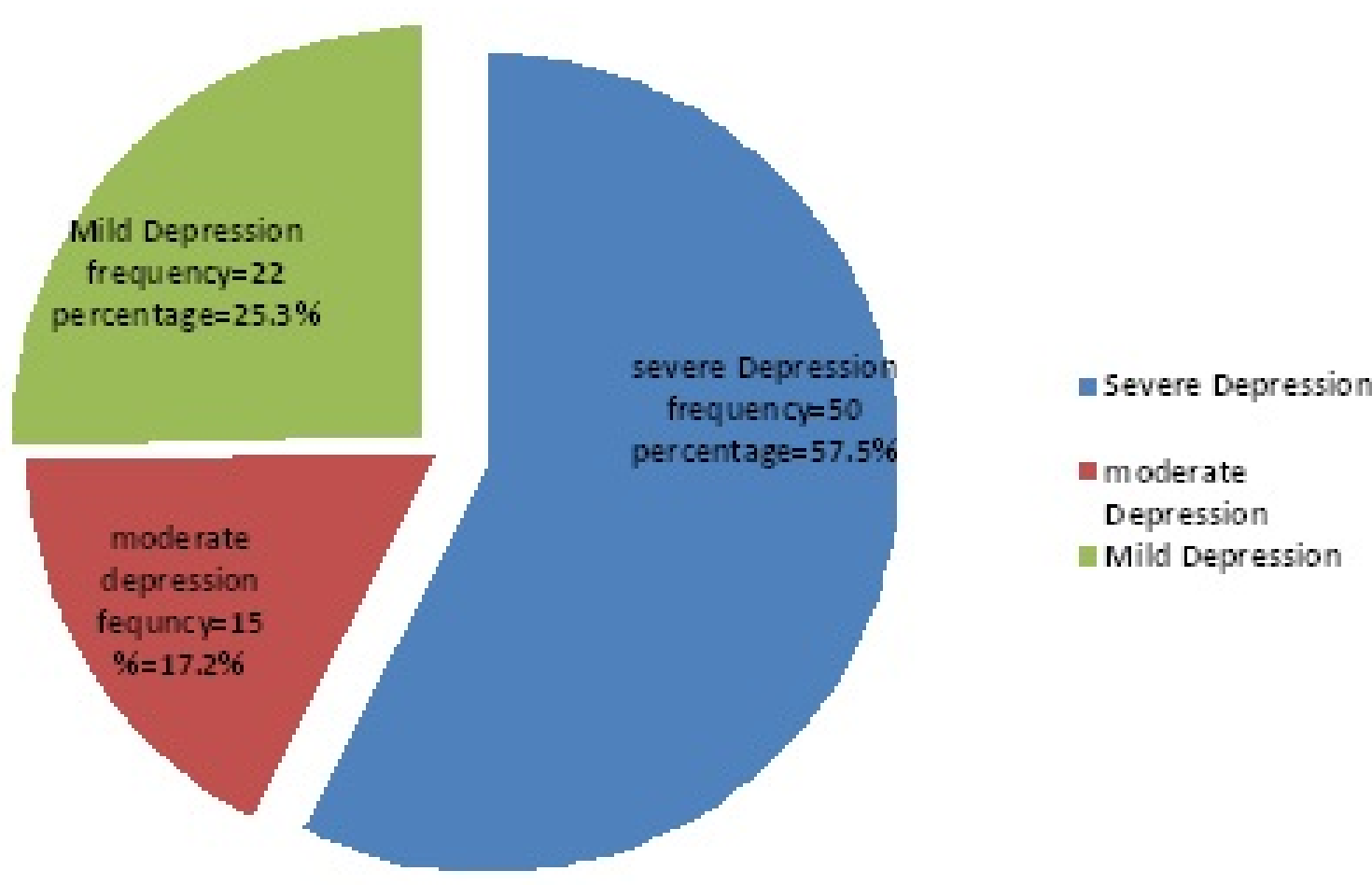

Figure 2 above shows the distribution of various forms of depression among women who attended and received treatment at the Mental Health Clinic: $22(25.3 \%)$ had mild depression, $15(17.2 \%)$ had moderate depression while $50(57.5 \%)$ had severe form of depression.

Figure 2: Distribution of various forms of depressive disorders. 


\section{Limitation of the Study}

The study was conducted in a single unit and findings may not be transferable to the other regions of Nigeria. A further larger population survey is being advocated.

\section{Policy Implication}

Mental health policy makers and stake holders should address the plight of individuals and families living with mental illnesses, most notably how to increase access to mental health care services of sufficient quality to ensure effective treatments, both the continuity of and adherence to treatments.

\section{Conclusion}

Depression poses a substantial public health challenge, both at the social and economic levels as well as the clinical level. Barriers to effective care include the lack of resources, lack of trained providers, and the social stigma associated with mental disorders. However, evidence has shown that treating depression in primary care is feasible, affordable and costeffective, the key interventions are treatment with generic antidepressant drugs and brief psychotherapy will improve the lives of women suffering with the disorders. On an individual, community, and national level, it is time to educate ourselves about depression and support families and people living with the disease.

\section{References}

1. World Health Organization (2012) Mental Health and Substance Abuse. Conquering depression, Fact and figure, Geneva.

2. Berzoff J, Hayes M (2007) "Inside out and inside in psychodynamic", in Biopsychosocial Aspect of depression. Jason Arnoson Inc.

3. Marcelo JS, Henrique CK, Ana LK (2012) Socioeconomic conditions and risk of mental depression: An empirical analysis for Brazilian citizens. Economic Research International.

4. Demyttenaere K, Bruffaerts R, Posada-Villa J, Gasquet I, Kovess $V$, et al. (2004) Prevalence, severity, and unmet need for treatment of mental disorders in the World Health Organization World Mental Health Surveys, JAMA 291: 2581-2590.
5. Mirza 11, Jenkins R (2004) Risk factors, prevalence, and treatment of anxiety and depressive disorders in Pakistan: systematic review. BMJ 328: 794.

6. World Health Organization (2008) The Global Burden of Disease. Available http://www.who.int/healthinfo/ global_burden_disease/GBD. Accessed 26 October 2015.

7. Adler DA, McLaughlin TJ, Rogers WH, Chang $H$, Lapitsky L, et al. (2006) Job performance deficits due to depression. Am J Psychiatry 163: 1569-1576.

8. Gilmour H, Patten SB (2007) Depression and work impairment. Health Rep 18: 9-22.

9. Ivanova JI, Birnbaum HG, Kidolezi Y, Subramanian G, Khan SA, et al. (2010) Direct and indirect costs of employees with treatmentresistant and non-treatment-resistant major depressive disorder. Curr Med Res Opin 26: 2475-2484.

10. Patel V (2001) Cultural factors and international epidemiology. Br Med Bull 57: 33-45.

11. Albert PR (2015) Why is depression more prevalent in women? J Psychiatry Neurosci 40: 219-221.

12. Araya R, Flynn T, Rojas G, Fritsch R, Simon G (2006) Costeffectiveness of a primary care treatment program for depression in low-income women in Santiago, Chile. Am J Psychiatry 163: 1379-1387.

13. Keita GP (2007) Psychosocial and cultural contributions to depression in women: considerations for women midlife and beyond. J Manag Care Pharm 13: S12-15.

14. Yusuf AF, Adeoye EA (2011) Prevalence and causes of depression among civil servants in Osun State, implication for counseling. Edo Journal of Counselling 4: 92-102.

15. Amoran O, Lawoyin $T$, Lasebikan $V$ (2007) Prevalence of depression among adults in Oyo State, Nigeria: a comparative study of rural and urban communities. Aust J Rural Health 15: 211-215.

16. Obi IE, Aniebue PN, Okonkwo K, Okeke TA, Ugwunna N (2015) Prevalence of depression among health workers in Enugu, South East Nigeria. Niger J Clin Pract 18: 342-347.

17. Poongothai S, Pradeepa R, Ganesan A, Mohan V (2009) Prevalence of depression in a large urban South Indian population--the Chennai Urban Rural Epidemiology Study (CURES-70). PLoS One 4: e7185. 